\title{
LA ETIMOLOGÍA DEL CÁNCER Y SU CURIOSO CURSO HISTÓRICO
}

\author{
Oswaldo Salaverry $1,2, \mathrm{a}$
}

\section{RESUMEN}

Se discuten las primeras descripciones de cáncer en la historia de acuerdo a recientes hallazgos y sus interpretaciones que lo muestra como un grupo de enfermedades raras hasta el siglo XVIII, cuando comenzó su incremento hasta los niveles actuales. La literatura médica muestra numerosos antecedentes de supuestas lesiones cancerosas que, en realidad, corresponden a otras lesiones. Parte de la explicación se refiere a un malentendido etimológico acerca de la palabra griega karkinos que significaba cáncer, en su sentido moderno, pero también lesión ulcerosa. Se revisa ampliamente esta confusión en la antigua literatura médica y luego se esbozan los principales hitos de la concepción moderna del cáncer hasta el siglo dieciocho.

Palabras clave: Etimología; Cáncer; Úlcera; Historia de la medicina (fuente: DeCS BIREME).

\section{CANCER ETYMOLOGY AND ITS HISTORICAL CURIOUS COURSE}

\section{ABSTRACT}

The first cancer descriptions in history are discussed according to recent findings and their interpretation, which show it as a group of unknown diseases until the 18th century, when it started to increase to actual levels. Medical literature shows a variety of what were considered cancer lesions, which are actually different lesions. This is partly due to an etymological misunderstanding of the Greek term karkinos that, in its modern sense, meant "cancer", but also ulcerative lesion. This confusion is widely reviewed in the ancient medical literature and the main landmarks of modern cancer conception up to the 18th century are outlined.

Key words: Etymology; Neoplasms; Ulcer; History of medicine (source: MeSH NLM).

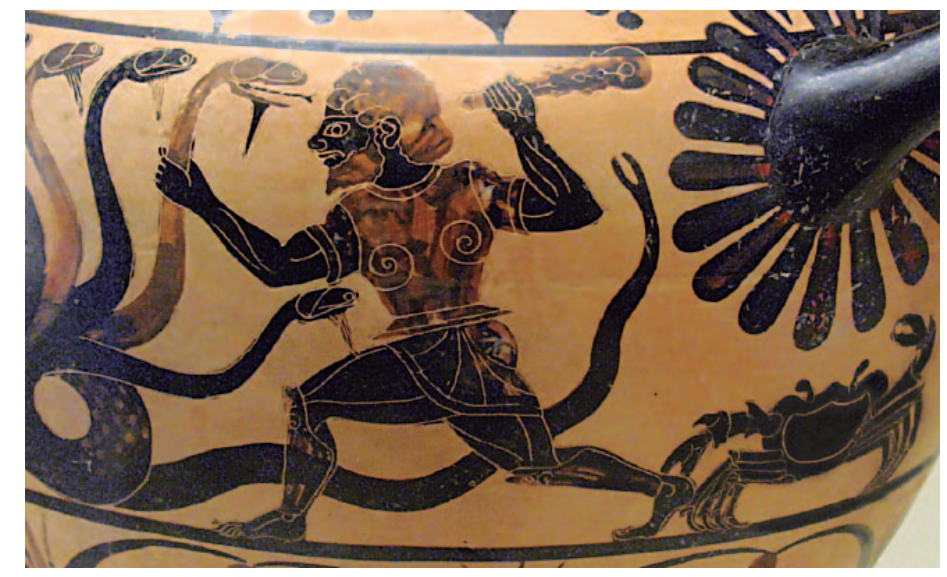

Batalla de Hércules contra la hidra y el cangrejo. Jarrón de agua (detalle). Periodo etrusco, 525 a. C.

Durante la lucha de Hércules contra la Hidra, la diosa Hera envió al karkinos (cangrejo) para ayudarla, pero Hércules lo aplastó con su talón. Hera recompensó la fidelidad del cangrejo elevándolo al cielo como la constelación de Cáncer.

Fuente: J. Paul Getty Museum (disponible en www.getty.edu).

\footnotetext{
Centro Nacional de Salud Intercultural, Instituto Nacional de Salud. Lima, Perú.

2 Facultad de Medicina, Universidad Nacional Mayor de San Marcos. Lima, Perú

a Médico doctor en Medicina

Recibido: 06-03-13 Aprobado: 20-03-13
}

Citar como: Salaverry O. La etimología del cáncer y su curioso curso histórico. Rev Peru Med Exp Salud Publica. 2013;30(1):137-41. 


\section{INTRODUCCIÓN}

El cáncer es, sin duda, un problema de salud pública global y, a pesar de los esfuerzos realizados, continúa afectando y matando a un enorme número de personas sin distinción alguna. Se ha constituido, por tanto, en un punto de confluencia de las más diversas especialidades biomédicas, y entre ellas no está exenta la historia de la medicina, que muestra los diversos esfuerzos realizados desde hace siglos para identificarlo y enfrentarlo. No es un debate menor el que busca conocer el origen del cáncer, pero no desde una perspectiva fisiopatológica sino como una enfermedad que surge históricamente en un momento y circunstancias determinadas. Esa precisión, de carácter histórico-social, sin duda contribuirá a una mejor estrategia para enfrentarlo como un problema contemporáneo.

\section{EL CÁNCER EN LA PREHISTORIA Y LAS CIVILIZACIONES EXTINTAS}

La paleopatología brinda alguna evidencia de lesiones compatibles con el cáncer en humanos desde hace 150000 años ${ }^{(1)}$, aunque también muestra que era una enfermedad poco frecuente, que se habría incrementado a consecuencia de los cambios medioambientales desde el siglo XVIII (2). Existe controversia sobre si las lesiones óseas prehistóricas son realmente consecuencia del cáncer o corresponden a otras etiologías ${ }^{(3,4)}$.

No tenemos información sobre la interpretación primitiva del cáncer o si se intentaba algún tipo de terapia, pero el estudio de la mentalidad primitiva permite suponer que al igual que con otras manifestaciones patológicas se atribuía estas lesiones -que aparecían sin relación con traumatismos o causas identificables- a fuerzas sobrenaturales. Se ha postulado que su rareza en la prehistoria se debería a la escasa expectativa de vida, y la mayor incidencia de enfermedades infecciosas, aunque el argumento es rebatido por la existencia de múltiples formas de cáncer juvenil, que tampoco se describen en los registros encontrados.

En las primeras civilizaciones, en Sumeria y Egipto, la interpretación de la enfermedad continuó siendo sobrenatural pero en un formato de religiosidad más compleja, los dioses menores y mayores del mundo mesopotámico, en muchos casos, representaban o tenían como atributo de su poder las enfermedades más frecuentes y temidas, así, existían dioses de la peste, de las enfermedades de transmisión sexual, y otros específicos para las dolencias de parturientas y niños ${ }^{(5)}$. Llama la atención que no existiera un dios específico para las enfermedades tumorales o cancerosas, lo que abona en el sentido de su escasa ocurrencia.
En Egipto, los médicos se formaban y agrupaban en las "casas de la vida", mezcla de templo y escuela, en ellas llegaron a desarrollar una cierta especialización médica con expertos para diversas dolencias que, debemos suponer, eran las más frecuentes; entre ellas, enfermedades oculares e incluso parasitarias, pero no existía un especialista en tumoraciones. Pese a ello, la literatura médica ha repetido incansablemente que en dos de los llamados "papiros médicos", se reconoce el cáncer. Lo cierto es que si leemos directamente los textos queda claro que las lesiones descritas en el papiro de Edwin Smith son de lesiones ulcerosas, tórpidas pero en modo alguno asimilables a lesiones cancerosas según criterios contemporáneos, mientras que en el papiro de Ebers, solo se hace mención a tumores de mama (por cierto, en varones) y que más parecen corresponder a lesiones ulceradas ${ }^{(5)}$. Frente a esta evidencia, la persistencia en la distorsión se explica por la inexistencia de una entidad clínica claramente diferenciada a la que en la antigüedad se definiera como cáncer. Las posibilidades técnicas de médicos egipcios y mesopotámicos los limitaban al tratamiento de afecciones externas, y las diversas heridas oulceraciones recibían un tratamiento similar y una denominación común, correspondiente a lesiones ulceradas o formas de cáncer. Cuando dichos textos, siglos después fueran traducidos por expertos orientalistas, estos asimilaron los términos que se referían a hinchazones y úlceras con las palabras con que se denominaban en el siglo $\mathrm{XIX}$ estas lesiones, llamándolas tumores, y cáncer en otros casos.

\section{LA GRECIA CLÁSICA}

Algunos milenios después, en el siglo IV a.C., en los escritos hipocráticos encontramos no solo las primeras descripciones sino también el origen etimológico de la palabra cáncer. En el Corpus Hippocraticum, colección de obras atribuidas a Hipócrates, se menciona unas lesiones ulcerosas crónicas, algunas veces endurecidas, que se desarrollan progresivamente y sin control (6) expandiéndose por los tejidos semejando las patas de un cangrejo, por lo que las denominó con la palabra griega каркі́vos (se lee karkinos) (7) dándole un significado técnico a la palabra griega cangrejo que se escribe igual. De allí, el término pasa al latín como "cancer" (en latin sin acento) con ambos significados, el del animal y el de úlcera maligna o cáncer en el sentido moderno. Siglos después, al formarse el castellano se derivan de la palabra latina dos términos separados. Por una parte, usando un sufijo diminutivo, se forma la palabra cangrejo para denominar al crustáceo y, por otra parte, se consolida el término "cáncer" como un término médico para un tipo determinado de lesión (en latín Cancer cancri m. Cancer a similitudine maritimi animalis vocatum) ${ }^{(8)}$. 
Pero ¿Qué era el kapkívos, o su palabra derivada

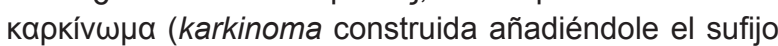
$\omega \mu \alpha$ : tumor) para un médico griego? En esencia, era una úlcera externa de difícil curación, no necesariamente lo que hoy entendemos por una lesión cancerosa; debe recordarse que no se encuentra referencia a lesiones internas designadas con la palabra karkinos. La doble acepción de la palabra karkinos, usada para describir diferentes úlceras pero también el cáncer, ha sesgado la literatura médica que, cada vez que ha encontrado la palabra cáncer o karkinos en textos médicos de la antigüedad, le atribuye el sentido moderno de cáncer y, por tanto, la condición de precursora en la descripción de diferentes lesiones cancerosas, cuando es muy probable que se refieran solo a úlceras de difícil tratamiento.

Un ejemplo es el párrafo de Hipócrates dedicado a la ictericia en los Aforismos Hipocráticos: Si en la ictericia el hígado se pone duro es mala señal. Si persiste esa ictericia puede ser debida al cáncer (karkinos) o cirrosis hepática, enfermedades ambas que ocasionan endurecimiento y aumento del volumen del hígado ${ }^{(9)}$. En otro escrito de Hipócrates, "Sobre las enfermedades de las mujeres" describe el cáncer de mama, usando también el término karkinos: /.../En las mamas se producen unas tumoraciones duras, de tamaño mayor o menor, que no supuran y que se van haciendo cada vez más duras; después crecen a partir de ellas unos cánceres (karkinos), primero ocultos, los cuales por el hecho de que van a desarrollarse como cánceres (karkinos), tienen una boca rabiosa y todo lo comen con rabia ${ }^{(10)}$.

Existen otras palabras dentro del rico vocabulario médico griego que tienen actualmente relación con el cáncer: la raíz ǒүкоৎ o "hinchazón" (se lee oncos), fue utilizada en la antigüedad no para describir algún tipo de lesión ulcerosa o el cáncer sino como la simple denominación de la hinchazón o edema, lo que luego en latín se traduciría como "tumor", uno de los signos de la inflamación; así, Celso (25 a.C. -50 d.C.) en su obra De re medica libri octo (sobre la medicina) lo incluye como uno de los cinco signos clásicos de la inflamación. Hacia mediados del siglo XIX surge a partir de este palabra griega un neologismo: oncología como el estudio de los tumores, sean estos malignos o no ${ }^{(11)}$.

El tratamiento del karkinos en época hipocrática era básicamente local y herbolario y, en muchos casos, se recomendaba no hacer nada, hasta que surge Galeno (129-157 d.C.) el sistematizador de la medicina griega, quien publica un libro dedicado exclusivamente a los tumores: De tumoribus praeter naturam (peri ton para physim onkom) ${ }^{(12)}$, en el cual describe diversas lesiones tumorales u onkoi ${ }^{(13)}$. Dentro de su concepción humoral considera que las tumoraciones cancerosas son resultado de una alteración del humor "bilis negra" (14). Siguiendo la tradición terapéutica se debe ayudar al cuerpo a que elimine este "humor alterado" para lo cual se usa la cirugía bien sea por exéresis o cauterizando con fuego, pero también sustancias que ayuden a su expulsión.

\section{EL MEDIOEVO Y EL RENACIMIENTO}

Los últimos años del Imperio romano no muestran un incremento de los casos de cáncer, que continua siendo una enfermedad rara, como lo demuestran estudios en cementerios de la época ${ }^{(15)}$. Durante el periodo medieval Europa, por influencia del cristianismo, se aleja del naturalismo científico griego por considerarlo pagano y contrario a la omnipotencia divina, esto produce una acelerada pérdida de conocimientos médicos al tiempo que la mentalidad cristiana propone una desvalorización del cuerpo, lastre material del espíritu, y una visión milagrista de la salud. Los escasos reportes de casos clínicos medievales no muestran evidencias adecuadas de la prevalencia y el tratamiento del cáncer, se describen episodios aislados y la terapéutica continúa siendo herbolaria y local. Un caso conocido es el del papa Gregorio $X$ quien presentaba una lesión cutánea que podría ser un melanoma y que recibió tratamiento con un ungüento a base de arsénico, que lo aliviaría al menos ocho años, hasta que muere por otras causas ${ }^{(16)}$.

En la orilla opuesta del Mediterráneo los árabes sí asimilan la medicina griega y le dan una forma nueva. Basándose en la idea de expulsar el humor alterado proponen su tratamiento quirúrgico además de la cauterización con fuego y la sangría, con la intención de acelerar la expulsión de los humores corruptos del organismo. Los árabes usan la terminología latina y tienen una sola palabra para denominar tanto al cangrejo como el cáncer: saratán, de donde se origina el vocablo castellano antiguo zaratán que en la España renacentista será sinónimo popular de cáncer, aunque luego se restringe al cáncer de mama.

El renacimiento, con su regreso a las fuentes originarias de la cultura griega, no significó un cambio notable en la identificación del cáncer o en su tratamiento, las enfermedades epidémicas eran las más temidas y, por tanto, el cáncer se seguía tratando con medidas generales contra el desorden humoral subyacente; y en el caso de lesiones externas con las cauterizaciones. La cirugía relegada por siglos y en manos de empíricos no tiene mucho que ofrecer en este periodo, las cauterizaciones con hierro caliente eran aplicadas por los cirujanos o los barberos, casi siempre sin resultado. 


\section{EL EXTRAORDINARIO SIGLO XVIII}

Desde el renacimiento se inicia un movimiento naturalista y progresivamente experimental en la medicina. La nueva anatomía con Vesalio, la circulación de la sangre con Harvey y el descubrimiento de un mundo infinitesimal solo visible al microscopio conducen paulatinamente hacia el reconocimiento de enfermedades diferenciadas donde antes solo se reconocía "fiebres" y "caquexias". Los reportes de cáncer son más precisos y se puede distinguir como una especie morbosa diferenciada.

Se deberá esperar hasta el siglo XVIII para que se ordene tanto la identificación de las lesiones cancerosas, ahora sí bien diferenciadas como cáncer, y especialmente su tratamiento con plantas medicinales; un ejemplo es el uso de la cicuta postulada por Storck (17), pero cuando no pudo demostrar evidencias de su eficacia lo atribuyó a que la variedad adecuada solo se conseguía en Viena. Este es un ejemplo y el inicio de múltiples medicamentos secretos que se postulan en la época, tal como los describe Burrows ${ }^{(18)}$ y Cullen ${ }^{(19)}$, quien en particular incluye la belladona, el opio y otros medicamentos hoy prohibidos.

\section{LAS TEORÍAS MODERNAS}

En 1775 Percival Pott señaló la relación existente entre de cáncer del escroto y el polvo de carbón entre los deshollinadores ${ }^{(20)}$, generalmente niños prepúberes, que luego cuando ya no podían deslizarse por las estrechas chimeneas sufrían unas lesiones En la parte inferior del escroto; donde produce una llaga superficial, dolorosa, de mal aspecto con bordes duros y elevados que en poco tiempo invaden la piel del dartos, y las membranas del escroto, y alcanza el testículo, que crece y se endurece... Cuando llega al abdomen, afecta alguna víscera y pronto se vuelve dolorosamente destructivo (21).

En 1855 Rudolph Virchow, quien había demostrado que toda célula proviene de otra célula, sugirió que las células cancerosas debían derivar de otras células ${ }^{(22)}$. Su discípulo Julius Cohnheim desarrollaría posteriormente la idea y hoy es reconocido como el autor de la teoría de la células embrionarias durmientes o residuales, basándose en la gran similitud en las forma de proliferación de ambos tipos de tejido, aunque naturalmente en el cáncer la diferenciación se alteraba ${ }^{23)}$. Los hitos posteriores son importantes: Johannes Müller observó el carácter desordenado de las células cancerosas. Henri Le Fran observó la diseminación por los nódulos linfáticos y de allí a la circulación general, mientras que Wilhelm Waldeyer mostró en 1800 el rol de los émbolos sanguíneos pasando del tumor a los vasos y linfáticos.
En 1911 Peyton Rous aisló el sarcoma en el pollo y lo trasplantó a otros a través de un preparado filtrado carente de células iniciando así la teoría viral del origen del cáncer; mientras que Dennis Burkitt en África central encontró un linfoma que solo existía en ciertos climas y ambientes por lo que sugirió un virus transmitido por mosquitos. Años después se encontró el virus EB oncogénico de la familia de los herpes virus pero luego se descubrió que este mismo virus daba origen a diversos canceres en otros lugares, como el carcinoma nasofaríngeo en China ${ }^{(24)}$.

\section{LA TERAPÉUTICA DEL CÁNCER EN EL SIGLO XIX}

A comienzos de siglo XIX la escasa comprensión de la naturaleza del cáncer y el paralelo auge de la cirugía y los conceptos que esta traía, como la asepsia, impulsaron un pensamiento terapéutico contra el cáncer basado en su cauterización. Muy diversos agentes fueron utilizados por los médicos como una alternativa a la escisión quirúrgica, entre ellos pastas mercuriales y arsenicales, ácidos minerales concentrados, (incluyendo el nítrico y el sulfúrico), la potasa, la cal sólida y otros más aplicándolos sin una técnica particular a las lesiones cancerosas, causando en muchos casos un gran sufrimiento.

Uno de los primeros métodos estandarizados de esta terapia escarificante, que reemplazaba la escisión quirúrgica, es el propuesto por Canquoin en 1838 utilizando el cloruro de zinc ${ }^{(25)}$. Su trabajo basado en una casuística de más de 600 casos utilizaba cuatro pastas de cloruro de zinc con harina común, cada una con una diferente concentración. Estas se aplicaban por etapas y por diferentes periodos en forma de líneas bien delimitadas en el cáncer por tratar. La intención era formar una escara lo más precisa posible que solo afectara la lesión cancerosa y no otros tejidos. La pasta de Canquoin, o el método del mismo nombre, se convirtió en un procedimiento ampliamente usado ya no solo para el cáncer sino, con ligeras variaciones, para el tratamiento de todo tipo de lesión ulcerosa. En el ámbito castellano se encuentran referencias a su uso en el cáncer hasta $1880^{(26)}$.

Surgieron otros métodos como el de Rivaille en 1850 (27) con ácido nítrico solidificado, y otros métodos incluso para canceres específicos como el método de D'Filhos para el cáncer de cuello uterino ${ }^{(28)}$. Uno de los más destacados cirujanos franceses de la época Velpau evaluó críticamente la cauterización concluyendo que a pesar de diversos inconvenientes era un método recomendable no solo en forma aislada sino a continuación de la cirugía. Son muy descriptivos los nombres de diversos compuestos utilizados entonces: 
Beurre d'antimoine o manteca de antimonio; Caustique de Vienne basado en cal y potasa, y el Caustique Filhos, generalmente mal traducido como "hijos cáusticos" cuando en realidad hace referencia al propulsor de este preparado de potasa el Dr. D'Filhos. El mismo recomienda un preparado que denomina Caustique noir ${ }^{(29)}$, basado en ácido sulfúrico mezclado con azafrán molido para darle consistencia pastosa.
La historia de los tratamientos del cáncer es mucho más amplia de lo que permite esta breve reseña, solo se debe mencionar que, paralelamente a los tratamientos racionales, aunque algunos de ellos de escasa efectividad, se ha generado una amplia oferta de curaciones extraordinarias, casi siempre auspiciadas por empíricos que afirman basarse en conocimientos e ingredientes secretos, lo que constituye por sí misma otra historia.

\section{REFERENCIAS BIBLIOGRÁFICAS}

1. Halperin EC. Paleo-oncology: the role of ancient remains in the study of cancer. Perspect Biol Med. 2004;47(1):1-14.

2. Capasso LL. Antiquity of cancer. Int J Cancer. 2005;113(1):2-13.

3. Micozzi MS. Disease in antiquity. The case of cancer. Arch Pathol Lab Med. 1991;115(8):838-44.

4. David AR, Zimmerman MR. Cancer: an old disease, a new disease or something in between? Nat Rev Cancer. 2010;10(10):728-33.

5. Lain P. Historia de la Medicina. Barcelona: Ed. Masson; 1998.

6. Hipocrates. Sobre las enfermedades de las mujeres. Tratados Hipocráticos Vol IV. Madrid: Ed. Gredos; 1988.

7. Sebastian Yarza F. Diccionario Griego español. Barcelona: Ed Ramon Sopena; 1984.

8. De Miguel. R. Nuevo diccionario latino - español etimológico. Madrid: Visor Libros, S.L. 1867.

9. Hipocrates. Aforismos. Tratados Hipocráticos Vol I. Madrid: Ed. Gredos; 1983.

10. Sobre las enfermedades de las mujeres. En: Hipocrates. Tratados ginecológicos. Volumen IV. Madrid: Editorial Gredos; 1988. p.133.20.

11. Keil H. The historical relationship between the concept of tumor and the ending -oma. Bull Hist Med. 1950;24(4):352-77.

12. Adams. Galeno. Complete works. London; 1856
13. Harding F. Breast Cancer. Causeprevention-cure. Aylesbury: Fred Harding; 2007.

14. Galeno. La Bilis Negra. En: Ruiz A. Obras de Galeno. Vol XI. Tomo I Ed. Buenos Aires: Universidad de Buenos Aires; 1947. p. 113-37.

15. Minozzi S, Catalano P, Caldarini C, Fornaciari G. Palaeopathology of human remains from the Roman Imperial Age. Pathobiology. 2012;79(5):268-83.

16. MacGregor AB. The search for a chemical cure for cancer. Med Hist. 1966;10(4):374-85.

17. Störck A. An essay on the medicinal nature of Hemlock. London: Ed. J. Nourse; 1760.

18. Burrows J. A New Practical Essay on Cancers: to which is also added, a new, more safe, and efficacious method of administring hemlock. London: Gale Ecco, Print Editions; 1767.

19. Cullen W. Tratado de materia médica del Dr. Cullen. Tomo III. Madrid; 1795.

20. Waldron HA. A brief history of scrotal cancer. Br J Ind Med. 1983;40(4):390-401.

21. Pott P. Chirurgical observations. Vol 3. London: L Hawes, W Clark, R Collins; 1775. p. 177-83.

22. Virchow R. Editorial. Virchows Arch Pathol Anat Physiol Klin Med. 1855;3:23.

23. Cohnheim J. Ueber entzundung und eiterung. Path Anat Physiol Klin Med. 1867;40:1-79.
24. Jaramillo, J. El cáncer. Fundamentos de oncología. San José de Costa Rica: Universidad de Costa Rica; 1991.

25. Parker P. The modern treatment of cancerous disease by caustics or enucleation. London: John Churchill \& Sons. 1867.

26. Anales de la Real Academia de Medicina. Madrid: Real Academia de Medicina; 1880. p. 178.

27. Rivallie A. Traitement du cáncer et des affections scrofuleuses par l'acide nitrique solidifié: suivi de réflexions sur les avantages de l'emploi de l'alum dans le pansement des plaies. París: Ed. Germer-Bailliére; 1850.

28. Filhos MJB. De la cautérisatrion du Col de l'Uterus avec le caustique solidifié de Potasse et de Chaux. Extrait de la Revue Medicale. París: Ed Edouard Bautruche; 1847.

29. Velpeau A. Traite des maladies du sein et de la región mammaire. París: Ed Victor masson; 1854.

Correspondencia: Oswaldo Salaverry García Dirección: Calle Cápac Yupanqui 1400, Lima 11, Perú.

Teléfono. (511) 617-6200 anexo: 1609

Correo electrónico: oswaldosalaverry@gmail.com 